\title{
Dietas com mananoligossacarídeo e níveis reduzidos de cálcio para codornas japonesas
}

\author{
Maria Cristina de Oliveira ${ }^{1}$, Milena Garcia Machado ${ }^{1}$, Bruno Nunes Gonçalves ${ }^{2}$, Carlos \\ Marques Rodrigues Macedo ${ }^{1}$, Francisco Alves de Assis ${ }^{1}$
}

\footnotetext{
${ }^{1}$ Faculdade de Medicina Veterinária - Universidade de Rio Verde.

${ }^{2}$ Faculdade de Zootecnia - Universidade de Rio Verde.
}

RESUMO - Avaliaram-se os efeitos de níveis de cálcio e da suplementação de dietas com mananoligossacarídeos sobre desempenho e a viabilidade econômica de codornas em postura. Foram utilizadas 200 codornas em delineamento inteiramente casualizado e arranjo fatorial $2 \times 2+1$, com dois níveis de cálcio (2,2 e 1,9\%), dois de mananoligossacarídeos ( 0 e $0,1 \%)$ e uma dieta controle (sem mananoligossacarídeos e com $2,5 \%$ de cálcio) com quatro repetições. Não houve efeito dos níveis de cálcio nem de mananoligossacarídeos sobre o peso dos ovos, a porcentagem de gema e albúmen e o preço da ração consumida/dúzia. A interação controle $\times$ fatorial foi significativa para consumo diário de ração, conversão alimentar e margem bruta. Codornas alimentadas com dietas pobres em cálcio e sem mananoligossacarídeos consumiram mais ração e tiveram pior conversão alimentar em comparação às aves alimentadas com a dieta controle, o que causou pior margem bruta. A redução dos níveis de cálcio diminuiu a produção e a massa de ovos, piorou a conversão alimentar (kg/kg) e reduziu a porcentagem de casca de ovo. A inclusão de mananoligossacarídeos reduziu o consumo diário de ração, melhorou a conversão alimentar (kg/dúzia) e aumentou a margem bruta, como reflexo do menor consumo diário de ração e da menor conversão alimentar. Dietas com 2,2\% de cálcio e suplementadas com 0,1\% de mananoligossacarídeos podem ser adotadas para codornas japonesas em postura.

Palavras-chave: nutrição de aves, prebiótico, produção de ovos

\section{Diets with mannan oligosaccharides and reduced calcium levels for Japanese quails}

\begin{abstract}
The effects of calcium levels and diet supplementation with mannan oligosaccharides (MOS) on the performance and economic viability of laying quails were evaluated. Two hundred quails were used in a randomized complete design and $2 \times 2+1$ factorial arrangement. The treatments were two calcium levels (2.2 and $1.9 \%$ ), two MOS levels (0 and $0.1 \%$ ) and a control diet (with 2.5\% calcium and no MOS) with four replications. There was no effect of calcium or mannan oligosaccharide levels on egg weight, yolk and albumen percentage and the diet intake/price per dozen ratio. The control $\times$ factorial interaction was significant for daily ration intake (DRC), feed conversion and gross marginal (GM). Quails fed calcium deficient diets and without MOS, consumed more ration and had worst feed conversion than birds fed the control diet, which resulted in lower gross margin. The reduction in calcium levels decreased egg production and mass, increased the feed conversion $(\mathrm{kg} / \mathrm{kg}$ ) and reduced the eggshell percentage. Mannan oligosaccharides inclusion reduced the daily feed intake, improved the feed conversion $(\mathrm{kg} / \mathrm{dz})$ and increased the gross margin as a result of the lower daily feed intake and lower feed conversion value. Diets with $2.2 \%$ calcium and supplemented with $0.1 \%$ MOS can be used for Japanese quails.
\end{abstract}

Key Words: bird nutrition, egg production, prebiotic

\section{Introdução}

O cálcio contribui para o potencial de ação nas membranas celulares, está envolvido na síntese de DNA, na atividade enzimática e na liberação de neurotransmissores, é o principal componente do osso e, em aves, é o principal constituinte da casca do ovo (Tordoff, 2001).
Aves alimentadas com dietas deficientes em cálcio podem diminuir a produção de ovos, entretanto, em alguns casos, continuam a oviposição e o cálcio é removido dos ossos provocando osteoporose e até a morte (Sultana et al., 2007).

A exigência nutricional de cálcio é de 2,5\% para codornas japonesas em postura alimentadas com dietas contendo $2.900 \mathrm{kcal}$ de EM/kg (NRC, 1994) ou de 3,0 a 3,4\% de cálcio 
para codornas na fase de produção recebendo rações contendo 2.800 e $3.000 \mathrm{kcal}$ de $\mathrm{EM} / \mathrm{kg}$, respectivamente (INRA, 1999). Na literatura, há recomendações de 2,5\% de cálcio para aves de 56 a 112 dias de idade (Osman, 2003), de $3 \%$ para codornas de 72 a 142 dias (Kadam et al., 2006) e de 3,2\% de cálcio para maior produção e qualidade de ovos (Barreto et al., 2007).

Há várias dificuldades em estabelecer as exigências de cálcio, entre elas, o melhoramento genético da ave, a palatabilidade da ração e a habilidade da ave em ajustar o consumo de ração de acordo com suas necessidades diárias.

Os prebióticos são oligossacarídeos não-digestíveis que chegam intactos ao intestino grosso, onde serão fermentados resultando na produção de ácidos graxos de cadeia curta (AGCC), fontes de energia para as bactérias e células intestinais (Delzenne, 2003). O mananoligossacarídeo, derivado da parede celular da $S$. cerevisiae (Moran, 2004), modifica o ecossistema bacteriano com aumento das Bifidobacterium e Lactobacillus (Sun, 2004), suprime a atividade de bactérias putrefativas e reduz a formação de produtos tóxicos da fermentação, como amônia, aminas e nitrosaminas (Flickinger et al., 2003). A maturação do intestino, fator importante para que a ave se desenvolva fisiologicamente, está estreitamente relacionada à digestão e absorção de nutrientes no intestino delgado (Aptekmann et al, 2001), de modo que maior superfície de absorção intestinal pode ser obtida com o consumo de prebióticos (Santos et al., 2005).

O consumo de prebióticos pode aumentar a absorção paracelular de cálcio, pois os AGCC formados diminuem o pH luminal e o cálcio insolúvel e não-absorvido, vindo do intestino delgado, é ionizado e solubilizado. Além disso, os AGCC causam hipertrofia das células da mucosa aumentando a superfície de absorção do intestino (Kruger et al., 2003; Zafar et al., 2004).

Este trabalho foi realizado para avaliar os efeitos da redução dos níveis de cálcio e a suplementação com mananoligossacarídeos sobre o desempenho e a viabilidade econômica de codornas japonesas em início de postura.

\section{Material e Métodos}

O experimento foi realizado no Setor de Avicultura Alternativa da Universidade de Rio Verde, no período de 18 de maio a 10 de agosto de 2007.

Foram utilizadas 200 codornas fêmeas (Coturnix coturnix japonica), com idade inicial de 40 dias e peso médio de 126,18 g, durante 84 dias, divididas em três períodos de 28 dias. O delineamento experimental foi inteiramente casualizado em arranjo fatorial $2 \times 2+1$, composto de dois níveis de cálcio $\times$ dois níveis de mananoligossacarídeos (MOS) e uma dieta controle, com quatro repetições de dez aves.

Os tratamentos resultaram da combinação dos níveis de cálcio (2,2 e 1,9\%) e de mananoligossacarídeos (0 e 0,1\%), ActiveMOS (Biorigin, São Paulo, Brasil), e a dieta controle (sem mananoligossacarídeos e com 2,5\% de cálcio) (Tabela 1). As rações foram formuladas com base na composição dos ingredientes (Rostagno et al., 2005) para atender às exigências nutricionais das codornas (NRC, 1994), exceto os níveis de cálcio. Tanto a água quanto as rações foram fornecidas à vontade, com as rações distribuídas diariamente duas vezes ao dia, às $8 \mathrm{~h}$ e às $17 \mathrm{~h}$.

O programa de luz teve início no $40^{\circ}$ dia de idade, com fornecimento inicial de 14 horas de luz diária e com aumentos semanais de 30 minutos até atingir 17 horas de luz por dia, programa que foi mantido até o final do período experimental.

As variáveis avaliadas foram: consumo diário de ração (g/ave/dia), produção de ovos (\%), peso do ovo (g), massa de ovo (g/ave/dia), conversão alimentar (kg/kg e kg/dúzia), percentagem de gema, de albúmen e de casca e viabilidade econômica da redução dos níveis de cálcio e da inclusão de mananoligossacarídeos às dietas.

A coleta de ovos foi feita diariamente às $17 \mathrm{~h}$. $\mathrm{O}$ peso médio dos ovos foi calculado por meio da pesagem de todos os ovos íntegros produzidos em cada repetição durante os três últimos dias de cada período. Para obtenção dos componentes do ovo, foram avaliados dois ovos por repetição, coletados diariamente do total de ovos obtidos nos últimos três dias de cada período. Os dois ovos foram pesados individualmente e então quebrados. O peso da gema de cada ovo foi registrado e a respectiva casca foi lavada e seca ao ar para posterior obtenção do peso. O peso do albúmen foi obtido pela diferença entre peso do ovo e os pesos da gema e casca. Posteriormente, os pesos dos componentes foram convertidos em porcentagem do peso do ovo.

Os custos com alimentação foram calculados com base na quantidade de ração consumida pelas aves para a produção de 1 dúzia de ovos. Esses valores foram obtidos multiplicando-se o custo médio de $1 \mathrm{~kg}$ de cada dieta pela conversão alimentar das aves submetidas à respectiva dieta. A viabilidade econômica foi calculada considerando o preço do quilo de ração (custo) e o preço da dúzia de ovos (receita). A margem bruta foi obtida subtraindo-se o custo da receita bruta. O preço de venda da dúzia de ovos, considerado no cálculo, foi de $\mathrm{R} \$ 0,60$.

Os resultados foram submetidos à análise de variância utilizando-se o programa Statsoft (1995) e a diferença 
Tabela 1 - Composição e preço por quilo das dietas experimentais

\begin{tabular}{|c|c|c|c|c|c|}
\hline \multirow[b]{3}{*}{ Ingrediente } & \multicolumn{5}{|c|}{ Dieta } \\
\hline & \multicolumn{3}{|c|}{ Sem mananoligossacarídeo } & \multicolumn{2}{|c|}{ Com $0,1 \%$ de mananoligossacarídeo } \\
\hline & $2,5 \% \mathrm{Ca}$ & $2,2 \% \mathrm{Ca}$ & $1,9 \% \mathrm{Ca}$ & $2,2 \% \mathrm{Ca}$ & $1,9 \% \mathrm{Ca}$ \\
\hline Farelo de soja & 34,50 & 34,50 & 34,50 & 34,50 & 34,50 \\
\hline Óleo de soja & 3,64 & 3,64 & 3,64 & 3,64 & 3,64 \\
\hline Fosfato bicálcico & 1,30 & 1,30 & 1,30 & 1,30 & 1,30 \\
\hline DL-metionina $99 \%$ & 0,14 & 0,14 & 0,14 & 0,14 & 0,14 \\
\hline mananoligossacarídeos ${ }^{1}$ & 0,00 & 0,00 & 0,00 & 0,10 & 0,10 \\
\hline Inerte & 1,35 & 2,12 & 2,92 & 2,02 & 2,82 \\
\hline Suplemento mineral/vitamínico ${ }^{2}$ & 0,10 & 0,10 & 0,10 & 0,10 & 0,10 \\
\hline Antioxidante & 0,01 & 0,01 & 0,01 & 0,10 & 0,10 \\
\hline Fósforo disponível (\%) & 0,35 & 0,35 & 0,35 & 0,35 & 0,35 \\
\hline Relação cálcio:fósforo & 7,14 & 6,28 & 5,43 & 6,28 & 5,43 \\
\hline Lisina (\%) & 1,08 & 1,08 & 1,08 & 1,08 & 1,08 \\
\hline Metionina (\%) & 0,45 & 0,45 & 0,45 & 0,45 & 0,45 \\
\hline Preço (R\$/kg) & 0,46 & 0,46 & 0,46 & 0,47 & 0,47 \\
\hline
\end{tabular}

${ }_{1} 25 \%$ de mananoligossacarídeos.

2 Cada kg contém: vit. A - 1.769.550 UI; vit. D 3 - 427.327,50 UI; vit. E - 1.317,75 mg; vit. B1 - 335 mg; vit. B2 - 750 mg; vit. B6 - 415 mg; vit. B12 - 2.000 mcg; vit. K - 301 mg; ácido nicotínico - 5.000 mg; pantotenato de cálcio - 2.000 mg; Cu - 1.852,65 mg; Fe - 9.315 mg; I - 142,74 mg; Mn - 12.006 mg; Se - 72,45 mg; Zn - 9.315 mg; metionina 198 g; antioxidante - 1,2 g.

${ }^{3}$ De acordo com Rostagno et al. (2005).

entre as médias do fatorial cálcio × mananoligossacarídeos foram determinadas por meio do teste $\mathrm{F}$ e entre as médias do fatorial $\times$ controle, pelo teste Dunnett, ambos a $5 \%$ de probabilidade.

\section{Resultados e Discussão}

Não houve efeito $(\mathrm{P}>0,05)$ das interações fatorial $\times$ controle e mananoligossacarídeos $\times$ cálcio sobre peso dos ovos (Tabela 2), resultados semelhantes aos de Kadam et al. (2006), que também não observaram diferenças nos pesos dos ovos entre os níveis de cálcio estudados (de 2,5 a 3,25\%) e diferem dos obtidos por Barreto et al. (2007), que notaram que o aumento dos níveis de cálcio de 1,6 para 3,6\% provocou aumento linear no peso do ovo. Quanto ao efeito do fornecimento de mananoligossacarídeos, Tarasewicz et al. (2004) avaliaram oligossacarídeos em dietas para codornas e observaram aumento no peso dos ovos quando incluíram $0,4 \mathrm{~g}$ do produto nas dietas de codornas, efeito associado ao melhor aproveitamento de nutrientes no intestino das aves.

A interação controle $\times$ fatorial foi significativa $(\mathrm{P}<0,05)$ para consumo diário de ração e para conversão alimentar (kg/kg e kg/dúzia). Codornas alimentadas com dietas deficientes em cálcio, sem suplementação com mananoligossacarídeos, consumiram mais ração e tiveram pior conversão alimentar em comparação às alimentadas com a dieta controle, provavelmente porque o nível de cálcio dietético interfere no consumo de ração em aves (Lobaugh et al., 1981; Tordoff, 2001). As aves que receberam os menores níveis de cálcio aumentaram seu consumo de ração na tentativa de aumentar a ingestão do mineral para atender suas exigências. Quando o mananoligossacarídeo foi adicionado à ração, o consumo se igualou ao observado nas aves ingerindo a dieta controle, provavelmente devido ao mecanismo de aumento de solubilidade do cálcio e hipertrofia das celulas intestinais como citado anteriormente (Juskiewicz et al., 2004; Suzuki \& Hara, 2004; Zafar etal., 2004). Esses dois efeitos podem ter permitido que adequados níveis de cálcio circulantes fossem atingidos na ave, reduzindo ou anulando os efeitos do consumo de dietas deficientes em cálcio. Esses resultados corroboram, em parte, os verificados por Barreto et al. (2007), que relataram piora na conversão alimentar $(\mathrm{kg} / \mathrm{kg})$ quando níveis de 1,6 a 2,8\% de cálcio foram utilizados e diferem dos obtidos por Pizzolante et al. (2007), que avaliaram dietas com níveis de 1,25: 2,50 e 3,75\% de cálcio e não observaram diferenças no consumo de ração ou na conversão alimentar.

A redução dos níveis de cálcio diminuiu $(\mathrm{P}<0,01)$ em $9,50 \%$ a produção de ovos e em $22,93 \%$ a massa de ovos, e 
Tabela 2 - Desempenho de codornas japonesas recebendo dietas com níveis reduzidos de cálcio com e sem inclusão de mananoligossacarídeo (MOS)

\begin{tabular}{|c|c|c|c|c|c|c|}
\hline \multirow[b]{2}{*}{ Parâmetro } & \multirow[b]{2}{*}{ Controle positivo } & \multirow[b]{2}{*}{ MOS } & \multicolumn{2}{|c|}{ Nível de cálcio (\%) } & \multirow[b]{2}{*}{ Média } & \multirow[b]{2}{*}{ CV $(\%)$} \\
\hline & & & 2,2 & 1,9 & & \\
\hline \multirow[t]{3}{*}{ Consumo de ração diário (g/ave/dia) } & & $0,0 \%$ & $29,37 *$ & $27,80 *$ & $28,59 \mathrm{a}$ & \\
\hline & & $0,1 \%$ & 25,13 & 26,29 & $25,71 b$ & \\
\hline & 24,43 & Média & 27,25 & 27,05 & & 5,72 \\
\hline \multirow[t]{3}{*}{ Produção de ovos (\%/ave/dia) } & & $0,0 \%$ & 81,85 & 71,55 & 76,70 & \\
\hline & & $0,1 \%$ & 80,92 & 75,76 & 78,34 & \\
\hline & 76,85 & Média & $81,38 a$ & $73,65 b$ & & 5,18 \\
\hline \multirow[t]{3}{*}{ Peso dos ovos (g) } & & $0,0 \%$ & 12,21 & 12,08 & 12,15 & \\
\hline & & $0,1 \%$ & 12,18 & 12,17 & 12,18 & \\
\hline & 12,32 & Média & 12,19 & 12,13 & & 3,92 \\
\hline \multirow[t]{3}{*}{ Massa de ovo (g/ave/dia) } & & $0,0 \%$ & 8,61 & 6,58 & 7,59 & \\
\hline & & $0,1 \%$ & 9,11 & 7,06 & 8,08 & \\
\hline & 8,22 & Média & $8,85 a$ & $6,82 b$ & & 9,45 \\
\hline \multirow[t]{3}{*}{ Conversão alimentar $(\mathrm{kg} / \mathrm{kg})^{1}$} & & $0,0 \%$ & 3,42 & $4,34 *$ & 3,89 & \\
\hline & & $0,1 \%$ & 2,76 & 3,85 & 3,31 & \\
\hline & 2,98 & Média & $3,09 \mathrm{~b}$ & $4,10 \mathrm{a}$ & & 7,60 \\
\hline \multirow{3}{*}{ Conversão alimentar (kg/dúzia) ${ }^{1}$} & & $0,0 \%$ & 0,44 & $0,47^{*}$ & $0,45 \mathrm{a}$ & \\
\hline & & $0,1 \%$ & 0,38 & 0,42 & $0,40 \mathrm{~b}$ & \\
\hline & 0,38 & Média & 0,41 & 0,44 & & 4,83 \\
\hline
\end{tabular}

Controle positivo = sem mananoligossacarídeo e com 2,5\% de cálcio.

$\mathrm{CV}=$ coeficiente de variação.

${ }^{1}$ Coeficiente de variação obtido com médias corrigidas $(\sqrt{ } \mathrm{X})$.

a,b Médias seguidas de letras diferentes, diferem entre si pelo teste $\mathrm{F}$.

* Difere da média do controle positivo pelo teste Dunnett.

piorou $(\mathrm{P}<0,02)$ a conversão alimentar $(\mathrm{kg} / \mathrm{kg})$ em $32,68 \%$. Esses resultados foram semelhantes aos de Sultana et al. (2007), que também verificaram redução na produção de ovos (de 61,61 para 59,03\%) com a redução dos níveis dietéticos de cálcio (de 3 para 2,5\%). Barreto et al. (2007) notaram efeito linear positivo na produção de ovos com o aumento do nível de cálcio dietético.

A inclusão de mananoligossacarídeo reduziu $(\mathrm{P}<0,02)$ o consumo diário de ração em 10,07\% e melhorou a conversão alimentar (kg/dúzia) em 11,11\%, possivelmente devido ao mecanismo já anteriormente descrito. A maior absorção de nutrientes faz com que o animal necessite de mais baixo consumo de ração para suprir suas exigências nutricionais.
Não houve efeito $(\mathrm{P}>0,05)$ das dietas sobre a porcentagem de gema e de albúmen (Tabela 3), porém, a redução dos níveis de cálcio diminuiu $(\mathrm{P}<0,05)$ a porcentagem de casca dos ovos, uma vez que $30 \%$ da casca do ovo de codorna é composta por cálcio (Barreto et al., 2007). O menor valor, entretanto, não diferiu daquele obtido com a dieta controle positivo.

Não houve efeito $(\mathrm{P}>0,05)$ das dietas sobre o preço do quilo de ração (Tabela 4) consumida por dúzia de ovos. A interação controle positivo $\times$ fatorial foi significativa $(\mathrm{P}<0,05)$ para margem bruta e a inclusão de mananoligossacarídeo aumentou $(\mathrm{P}<0,05)$ a margem bruta em $5,37 \%$. A margem bruta foi menor $(P<0,05)$ para aves alimentadas com a dieta com $1,9 \%$ de cálcio e sem

Tabela 3 - Qualidade dos ovos de codornas japonesas recebendo dietas com níveis reduzidos de cálcio com e sem inclusão de mananoligossacarídeo (MOS)

\begin{tabular}{|c|c|c|c|c|c|c|}
\hline \multirow[b]{2}{*}{ Parâmetro } & \multirow[b]{2}{*}{ Controle positivo } & \multirow[b]{2}{*}{ MOS } & \multicolumn{2}{|c|}{ Nível de cálcio (\%) } & \multirow[b]{2}{*}{ Média } & \multirow[b]{2}{*}{ CV (\%) } \\
\hline & & & 2,2 & 1,9 & & \\
\hline \multirow[t]{3}{*}{ Porcentagem de gema (\%) } & & $0,0 \%$ & 32,07 & 33,55 & 32,81 & \\
\hline & & $0,1 \%$ & 32,16 & 32,00 & 32,08 & \\
\hline & 31,95 & Média & 32,12 & 32,78 & & 3,72 \\
\hline \multirow[t]{3}{*}{ Porcentagem de albúmen (\%) } & & $0,0 \%$ & 59,31 & 57,92 & 58,61 & \\
\hline & & $0,1 \%$ & 59,22 & 60,54 & 59,88 & \\
\hline & 60,23 & Média & 59,26 & 59,23 & & 2,11 \\
\hline \multirow[t]{3}{*}{ Porcentagem de casca (\%) } & & $0,0 \%$ & 8,62 & 8,52 & 8,57 & \\
\hline & & $0,1 \%$ & 8,61 & 7,46 & 8,04 & \\
\hline & 7,81 & Média & $8,61 \mathrm{a}$ & $7,99 b$ & & 7,15 \\
\hline
\end{tabular}

Controle positivo = sem mananoligossacarídeo e com 2,5\% de cálcio.

$\mathrm{CV}=$ coeficiente de variação.

a,b Médias seguidas de letras diferentes, diferem entre si pelo teste F. 
Tabela 4 - Preço da ração consumida e margem bruta obtidos com o uso de dietas com níveis reduzidos de cálcio com e sem inclusão de mananoligossacarídeo (MOS) para codornas japonesas

\begin{tabular}{|c|c|c|c|c|c|c|}
\hline \multirow[b]{2}{*}{ Parâmetro } & \multirow[b]{2}{*}{ Controle positivo } & \multirow[b]{2}{*}{ MOS } & \multicolumn{2}{|c|}{ Nível de cálcio (\%) } & \multirow[b]{2}{*}{ Média } & \multirow[b]{2}{*}{ CV $(\%)$} \\
\hline & & & 2,2 & 1,9 & & \\
\hline \multirow[t]{2}{*}{ Preço da ração (US\$/dúzia) } & & $0,0 \%$ & 0,125 & 0,132 & 0,128 & \\
\hline & 0,107 & Média & 0,118 & 0,126 & & 9,54 \\
\hline \multirow[t]{3}{*}{ Margem bruta (US\$/dúzia) } & & $0,0 \%$ & 0,243 & $0,236 *$ & $0,240 \mathrm{~b}$ & \\
\hline & & $0,1 \%$ & 0,257 & 0,248 & $0,253 \mathrm{a}$ & \\
\hline & 0,261 & Média & 0,251 & 0,243 & & 2,09 \\
\hline
\end{tabular}

Preço da dúzia de ovos no atacado = US\$ 0,37.

Controle positivo = sem mananoligossacarídeo e com 2,5\% de cálcio.

$\mathrm{CV}=$ coeficiente de variação.

a,b Médias seguidas de letras diferentes, diferem entre si pelo teste $\mathrm{F}$.

*Difere da média do controle positivo pelo teste Dunnett.

mananoligossacarídeo em comparação à dieta controle. Esse resultado foi reflexo do efeito sobre a conversão alimentar em kg/dúzia, ou seja, as aves consumiram mais ração para produzir uma dúzia de ovos, piorando a margem bruta. A inclusão do mananoligossacarídeo aumentou $(\mathrm{P}<0,03)$ a margem bruta, como resultado do menor consumo de ração e da menor conversão alimentar em kg/dúzia, devido à presença do prebiótico nas rações.

\section{Conclusões}

É possível adotar dietas com 2,2\% de cálcio e suplementadas com $0,1 \%$ de mananoligossacarídeos para codornas japonesas em início de postura.

\section{Literatura Citada}

APTEKMANN, K.P.; ARTONI, S.M.B.; STEFANINI, M.A. et al. Morphometric analysis of the intestine of domestic quails (Coturnix coturnix japonica) treated with different levels of dietary calcium. Anatomia Histologia, Embryologia, v.30, p.277-280, 2001.

BARRETO, S.L.T.; PEREIRA, C.A.; UMIGI, R.T. et al. Determinação da exigência nutricional de cálcio de codornas japonesas na fase inicial do ciclo de produção. Revista Brasileira de Zootecnia, v.36, p.68-78, 2007.

DELZENNE, N.M. Oligosaccharides: state of the art. Proceedings of Nutrition Society, v.62, p.177-182, 2003.

FLICKINGER, E.A.; van LOO, J.; FAHEY JR., G.C. Nutritional responses to the presence of inulin and oligofructose in the diets of domesticated animals: a review. Critical Reviews in Food Science and Nutrition, v.43, p.19-60, 2003.

INSTITUT NATIONAL DE LA RECHERCHE AGRONOMIQUE INRA. Alimentação dos animais monogástricos: suínos, coelhos e aves. 2.ed. São Paulo: Roca, 1999. 245p.

JUSKIEWICZ, J.; ZDUNCZYK, Z.; JANKOWSKI, J. Selected parameters of gastrointestinal tract metabolism of turkeys fed diets with flavomycin and different inulin content. World's Poultry Science Journal, v.60, p.177-185, 2004.

KADAM, M.M.; MANDAL, A.B.; ELANGOVAN, A.V. et al. Response of laying Japanese quail to dietary calcium levels at two levels of energy. Journal of Poultry Science, v.43, p.351-356, 2006.

KRUGER, M.C.; BROWN, K.E.; COLLETT, G. et al. The effect of fructooligosaccharides with various degrees of polymerization on calcium bioavailability in the growing rat. Experimental Biology Medicine, v.228, p.683-688, 2003.

LOBAUGH, B.; JOSHUA, I.G.; MUELLER, W.J. Regulation of calcium appetite in broiler chickens. Journal of Nutrition, v.111, n.2, p.298-306, 1981.

MORAN, C.A. Functional components of the cell wall of Saccharomyces cerevisiae: applications for yeast glucan and mannan. In: ALLTECH'S ANNUAL SYMPOSIUM, 20., 2004, Lexington. Proceedings... Lexington: Alltech, 2004. p.280-296.

NATIONAL RESEARCH COUNCIL - NRC. Nutrients requirements of poultry. 9.rev.ed. Washington, D.C.: National Academy Press, 1994. 155p.

OSMAN, M. Effect of incorporating different calcium and phosphorus levels in quail diets on the performance, egg shell quality and incubation traits. Egyptian Poultry Science Journal, v.23, p.843-857, 2003.

PIZZOLANTE, C.C.; SALDANHA, E.S.P.B.; GARCIA, E.A. et al. Efeito do horário de fornecimento de rações contendo diferentes níveis de cálcio sobre o desempenho produtivo e qualidade de ovos de codornas japonesas (Coturnix japonica) em final de produção. Ciência Animal Brasileira, v.8, p.677-683, 2007.

ROSTAGNO, H.S.; ALBINO, L.F.T; DONZELE, J.L. et al. Tabelas brasileiras para aves e suínos: composição de alimentos e exigências nutricionais. 2.ed. Viçosa, MG: UFV, 2005. 186p.

SANTOS, F.S.; FARNELL, M.B.; TÉLLEZ, G. et al. Effect of prebiotic on gut development and ascites incidence of broilers reared in a hypoxic enviroment. Poultry Science, v.84, p.1092-1100, 2005.

STATSOFT. Statistic for windows (computer program manual). Tulsa: Stasoft Inc., 1995. (CD-ROM).

SULTANA, F.; ISLAM, M.S.; HOWLIDER, M.A.R. Effect of dietary calcium sources and levels on egg production and egg shell quality of japanese quail. International Journal of Poultry Science, v.6, p.131-136, 2007.

SUN, $X$. Broiler performance and intestinal alterations when fed drug-free diets. 2004. 59f. Dissertation (Master of Science in Animal and Poultry Science) - Faculty of the Virginia Polytechnic Institute, Blacksburg, 2004.

SUZUKI, T.; HARA, H. Various non-digestible saccharides increase intracellular calcium ion concentration in rat small-intestinal enterocytes. British Journal Nutrition, v.92, p.751-755, 2004.

TARASEWICZ, Z.; SZCZERBINSKA, D.; MAJEWSKA, D. et al. Assessment of the influence of oligosaccharides isolated from pea seeds on functional quality of quail. Czech Journal of Animal Science, v.49, p.257-264, 2004.

TORDOFF, M.G. Calcium: taste, intake, and appetite. Physiological Reviews, v.81, p.1567-1597, 2001.

ZAFAR, T.A.; WEAVER, C.M.; ZHAO, Y. et al. Nondigestible oligosaccharides increase calcium absorption and suppress bone resorption in ovariectomized rats. Journal of Nutrition, v.134, p.399-402, 2004. 